\title{
Double Hydrophosphination of Alkynes Promoted by Rhodium: the Key Role of an N-Heterocyclic Carbene Ligand
}

\author{
Andrea Di Giuseppe, ${ }^{* \mathrm{a}}$ Roberto De Luca, ${ }^{\mathrm{ab}}$ Ricardo Castarlenas, ${ }^{* \mathrm{ab}}$ Jesús J. Pérez-Torrente, ${ }^{\mathrm{a}}$ \\ Marcello Crucianelli, ${ }^{b}$ and Luis A. Oro* ${ }^{\text {ac }}$
}

The regioselective double hydrophosphination of alkynes mediated by rhodium catalysts is presented. The distinctive stereoelectronic properties of the NHC ligand prevent the catalyst deactivation by diphosphine coordination thereby allowing for the closing of a productive catalytic cycle.

Phosphines are ubiquitous ligands for transition-metal catalysts but general synthetic methods are still rather limited. ${ }^{1}$ In this context, transition-metal-catalysed $\mathrm{P}-\mathrm{H}$ bond addition to unsaturated compounds is probably one of the most interesting and fast developing areas for the straightforward atom economical synthesis of phosphines. ${ }^{2}$ Although several organometallic complexes have been shown to be efficient catalysts for the monohydrophosphination, ${ }^{3}$ or even double hydrophosphorylation ${ }^{4}$ or hydrophosphinylation, ${ }^{5}$ the direct double hydrophosphination of alkynes still remains a challenging reaction. ${ }^{2 \mathrm{~d}}$ In fact, 1,2-diphosphinoethane derivatives are one of the most significant family of ligands for the preparation of the most important homogeneous catalyst in the industrial chemistry. Synthetic methods are restricted to few processes, including the use of strong bases, ${ }^{6}$ or two step procedures. $^{5 \mathrm{a}-7}$ The biggest hurdle for the development of active organometallic catalysts in the double hydrophosphination of alkynes is indeed the reaction product. 1,2-diphosphines are chelating ligands with strong coordination ability for soft metal centres thereby inhibiting the organometallic catalyst. This problem has been elegantly circumvented by Nakazawa and coworkers that have developed the first transition-metal-based catalyst by using hard $\mathrm{Fe}^{\text {II }}$ complexes. ${ }^{8}$ However, the applicability of this system is limited to aromatic terminal alkynes. In this communication, we report the first example of a $\mathrm{Rh}^{\prime}$ complex bearing a $\mathrm{N}$ heterocyclic carbene (NHC) ligand able to catalyse the regioselective double hydrophosphination of terminal aromatic or aliphatic alkynes including substrates containing heteroatoms or a sensitive moiety as cyclopropane.

Our research group has recently reported highly active and selective Rh'-NHC catalysts for hydrofunctionalization reactions of unsaturated compounds. ${ }^{9}$ In particular, we have shown that complex $\left[\operatorname{Rh}(\mu-\mathrm{Cl})(\operatorname{IPr})\left(\eta^{2}-\text { coe }\right)\right]_{2} \quad$ (1a) $\quad$ (coe = cyclooctene, $\operatorname{IPr}=1,3$-bis-(2,6-diisopropylphenyl)imidazol-2carbene) is a very efficient catalyst for hydrothiolation of alkynes. ${ }^{9 a}$ We have now expanded the application of this catalytic system to hydrophosphination. As a model reaction we investigated the addition of diphenylphosphine (2) to phenylacetylene (3a) (molar ratio 1:1) in $\mathrm{C}_{6} \mathrm{D}_{6}$ at $80{ }^{\circ} \mathrm{C}$ catalysed by a $5 \mathrm{~mol} \%$ of complex $1 \mathrm{1a}$. The reaction was monitored by ${ }^{31} \mathrm{P} N M R$, which showed a $52 \%$ conversion after 24 hours (Scheme 1). Gratefully, it was found that 1,2bis(diphenylphosphino)-1-phenylethane (rac-phenphos) (7a), resulting from the double addition of diphenylphosphine to the alkyne, was the main product of the reaction (35\%) together with the expected mixture of vinylphosphines $\mathbf{4 a} \mathbf{a} \mathbf{5}$, and $6 a(1,23$, and $32 \%$, respectively). In addition, tetraphenylbiphosphine (8) was also observed (9\%), resulting from the dehydrocoupling of secondary phosphines, a wellknown transformation catalysed by several transition-metals including $\mathrm{Rh}^{10}$ Molecular hydrogen was released in the process that further reacts with phenylacetylene leading to styrene.

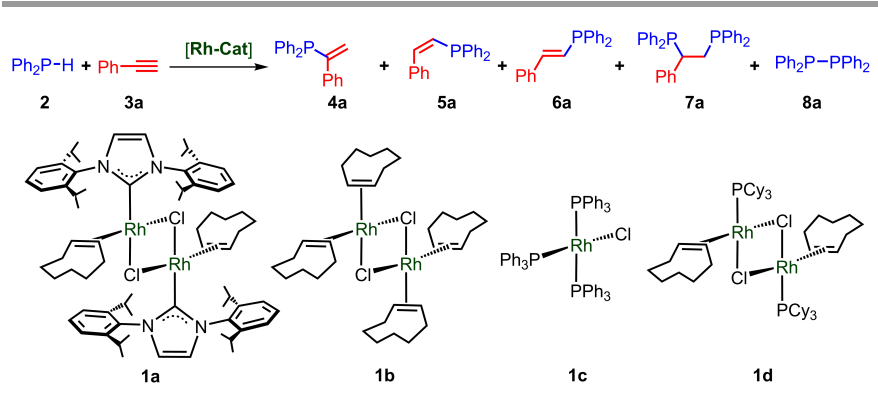

Scheme 1. Hydrophosphination of phenylacetylene with diphenylphosphine catalysed by $\mathrm{Rh}^{\prime}$ complexes.

\footnotetext{
${ }^{a}$ Departamento de Química Inorgánica, Instituto de Síntesis Química y Catálisis Homogénea (ISQCH) Universidad de Zaragoza-CSIC, C/ Pedro Cerbuna 12, 50009 Zaragoza (Spain).

${ }^{b}$ Dipartimento di Scienze Fisiche e Chimiche, Universitità dell'Aquila, Via Vetoio, I67100 Coppito (AQ) (Italy).

${ }^{c}$ Center for Refining and Petrochemicals, King Fahd University of Petroleum and Minerals, 31261 Dhahran (Saudi Arabia).

Electronic Supplementary Information (ESI) available: Synthesis, characterisation, and experimental details.
} 
Table 1. Reaction of phenylacetylene with diphenylphosphine catalysed by $\mathrm{Rh}$ complexes. $^{a}$

\begin{tabular}{ccccccc}
\hline Entry & Catalyst $^{b}$ & $\mathrm{~T}\left({ }^{\circ} \mathrm{C}\right)$ & ${\text { Conv. }(\%)^{c}}^{c}$ & $\mathbf{4 a / 5 a / 6 a ( \% ) ^ { d }}$ & $\mathbf{7 a}(\%)^{d}$ & $\mathbf{8}(\%)^{d}$ \\
\hline $1^{\mathrm{e}}$ & 1a & 80 & 60 & $2 / 20 / 15$ & 43 & 20 \\
2 & 1a & 120 & 90 & $0 / 6 / 4$ & 66 & 24 \\
3 & 1b & 120 & 47 & $6 / 51 / 35$ & 0 & 8 \\
4 & 1c & 120 & 45 & $6 / 25 / 48$ & 5 & 16 \\
5 & 1d & 120 & 59 & $4 / 21 / 36$ & 19 & 20 \\
\hline
\end{tabular}

${ }^{a}$ Reaction conditions: $0.1 \mathrm{mmol}$ of phenylacetylene, $0.2 \mathrm{mmol}$ of $\mathrm{Ph}_{2} \mathrm{PH}, 0.5 \mathrm{~mL}$ of toluene- $d_{8}, 120{ }^{\circ} \mathrm{C}, 24 \mathrm{~h}$ of reaction in a sealed NMR tube. ${ }^{b}[\mathrm{Rh}] /\left[\mathrm{PHPh}_{2}\right]=$ $0.05 .{ }^{C}$ Based on phosphine consumption, quantified by integration of the Inverse Gated Decoupled- ${ }^{31} \mathrm{P}$ NMR spectra. ${ }^{d}$ NMR selectivity in molar ratio. ${ }^{e} \mathrm{C}_{6} \mathrm{D}_{6}$

In order to maximize the amount of the diphosphine product $7 a$, the influence of the different variables of the reaction on the catalyst performance was studied and the most important results are reported in Table 1 (see full data in Table S1 of Supplementary Information). Modification of the $\left[\mathrm{Ph}_{2} \mathrm{PH}\right] /[\mathrm{PhC} \equiv \mathrm{CH}]$ ratio from $1: 1$ to $2: 1$ (entry 1 ) led to an increase of diphosphine $7 \mathrm{a}$ (43\%) versus monophosphinated products $(37 \%)$ together with an increment of $\mathbf{8}$. Noteworthy, a temperature rise from 80 to $120{ }^{\circ} \mathrm{C}$ (entry 2, toluene- $d_{8}$ ) was beneficial in terms both of activity and selectivity, resulting in a $90 \%$ of conversion with a $66 \%$ of selectivity towards $7 a$, along with a marked reduction of the monophosphinated products $(10 \%)$. The catalytic activity of a series of $\mathrm{Rh}^{\prime}$ complexes was studied in order to shed light into the effect of the NHC ligand on the catalytic performance of 1 a (entries 3-5). The presence of the carbene ligand seems to be fundamental for the preferential formation of 7a. In fact, $\left[\mathrm{Rh}(\mu-\mathrm{Cl})\left(\eta^{2}-\mathrm{coe}\right)_{2}\right]_{2}$ (1) b) was only able to catalyse the monophosphination of phenylacetylene, albeit with low conversion and selectivity (entry 3), whereas Wilkinson's catalyst $\mathrm{RhCl}\left(\mathrm{PPh}_{3}\right)_{3}(\mathbf{1 c})$ gave only $5 \%$ of 7 a (entry 4 ). The introduction of a stronger $\sigma$-donor and sterically encumbered phosphine such as triclyclohexylphosphine $\left(\mathrm{PCy}_{3}\right)(\mathbf{1 d})$ (entry 5) allowed for a better conversion (59\%) and selectivity towards the diphosphine (19\%) but lower than the Rh-NHC system. These results show that the $\mathrm{NHC}$ ligand confers to the catalyst the required stereoelectronic properties to catalyse efficiently the double hydrophosphination of phenylacetylene.

The scope of the reaction was studied for several types of alkynes including aromatic, aliphatic, or heteroatom containing substrates (Table 2). The presence of an electron-donating group in para position such as -OMe (3b) resulted in an increase of the reaction rate, $90 \%$ conversion after $12 \mathrm{~h}$ (entry 2 ), but was deleterious for the diphosphine selectivity (47\% of 7b). On the contrary, the presence of an electron-withdrawing group in para, $-\mathrm{CF}_{3}(\mathbf{3 c})$, or meta, -OMe (3d), led to a decrease of conversion (78 and 82\%, respectively) (entries 3 and 4), while the selectivity was not significantly affected.
Table 2. Hydrophosphination of alkynes catalysed by $1 a^{a}{ }^{a}$

\begin{tabular}{|c|c|c|c|c|c|c|}
\hline Entry & Alkyne & & Conv. $(\%)^{b}$ & $4 / 5 / 6(\%)^{c}$ & $7(\%)^{c}$ & $8(\%)^{c}$ \\
\hline 1 & & (3a) & 90 & $0 / 6 / 4$ & 66 & 24 \\
\hline 2 & & (3b) & $90^{d}$ & $0 / 7 / 14$ & 47 & 31 \\
\hline 3 & & $(3 c)$ & 78 & $0 / 8 / 2$ & 64 & 27 \\
\hline 4 & & (3d) & 82 & $0 / 11 / 5$ & 60 & 24 \\
\hline 5 & & (3e) & $66(83)^{e}$ & $\begin{array}{c}0 / 7 / 25 \\
(0 / 0 / 10)^{e}\end{array}$ & $\begin{array}{c}53 \\
(64)^{e}\end{array}$ & $16(26)^{e}$ \\
\hline 6 & & (3f) & 94 & $0 / 4 / 11$ & 60 & 25 \\
\hline 7 & & (3g) & 70 & $0 / 2 / 2$ & 47 & 49 \\
\hline 8 & & (3h) & 54 & $0 / 14 / 11$ & 0 & 75 \\
\hline 9 & & $(3 i)$ & 82 & $0 / 4 / 4$ & 38 & 47 \\
\hline 10 & & $(3 \mathbf{j})$ & 89 & 23 & 0 & 77 \\
\hline
\end{tabular}

${ }^{a}$ Reaction conditions: $0.1 \mathrm{mmol}$ of alkyne, $0.2 \mathrm{mmol}$ of $\mathrm{Ph}_{2} \mathrm{PH}, 5 \mathrm{~mol} \%$ of $1 \mathrm{a}$ in $0.4 \mathrm{~mL}$ of toluene $+0.1 \mathrm{~mL}$ of $\mathrm{C}_{6} \mathrm{D}_{6}, 120{ }^{\circ} \mathrm{C}, 24 \mathrm{~h}$ of reaction, sealed NMR tube. ${ }^{b}$ Based on phosphine consumption quantified by integration of the Inverse Gated Decoupled-31P NMR spectra. ${ }^{c}$ NMR selectivity in molar ratio. ${ }^{d} 12 \mathrm{~h}$ of reaction. ${ }^{e}$ $72 \mathrm{~h}$ of reaction.

The presence of a heteroatom in the aromatic ring, as in 2ethynylpyridine (3e), slowed down considerably the reaction leading to a conversion of $66 \%$ in $24 \mathrm{~h}$ (entry 5). After $72 \mathrm{~h}$ of reaction, conversion and selectivity reached a value quite similar to other electron poor alkynes. This can be justified both by the electron-withdrawing effect of pyridine or the ability of the nitrogen atom to coordinate to the rhodium center and inhibit the reaction. As previously noted, the double hydrophosphination of aliphatic alkynes still remains a goal to achieve. For this reason we have studied the reactivity of our catalytic system with a representative group of these substrates (entry 7-9). 1-Nonyne (3f) was successfully hydrophosphinated with good conversion (94\%) and a 60\% selectivity in $7 f$ (entry 6). Cyclopropylacetylene (3g) gave a slightly lower conversion (70\%) and selectivity (47\%), but the cyclopropyl group remained intact (entry 7). The double hydrophosphination reaction was inhibited with the bulkier tert-butylacetylene (3h), and the main product was the dehydrocoupled diphosphine 8 (entry 8). The presence of heteroatoms in the aliphatic backbone is perfectly tolerated. Thus, 3-dimethylamino-1-propyne (3i) gave an $82 \%$ conversion with an encouraging $38 \%$ of the diphosphine $\mathbf{7} \mathbf{i}$, in contrast to the results obtained for the ethynylpyridine, probably due to a lower coordination ability of the dimethylamino group. Internal alkynes, such as diphenylacetylene (3j), did not undergo double hydrophosphination (entry 10), being the phosphine dehydrocoupling reaction prevalent (77\% of $\mathbf{8})$. The new diphosphines $\mathbf{7 c}, \mathbf{d}, \mathbf{g}, \mathbf{h}$ were derivatized to the corresponding bis-borane adducts which were isolated by semi-preparative HPLC. 


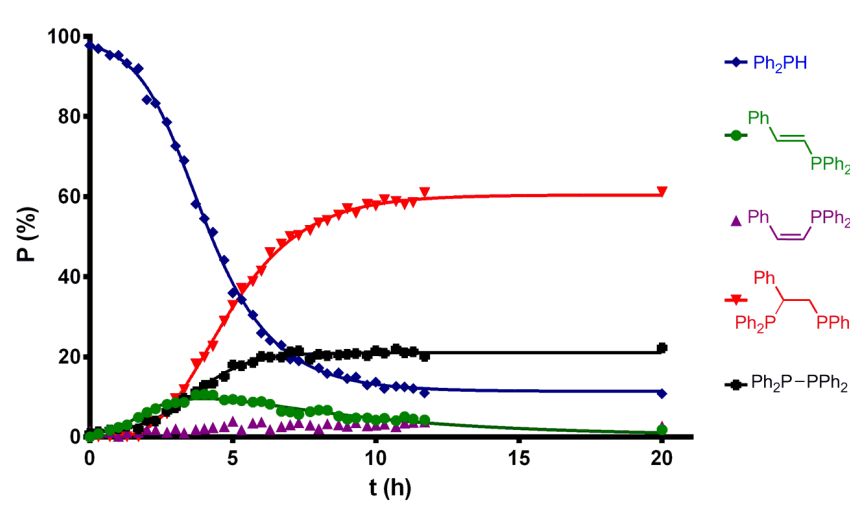

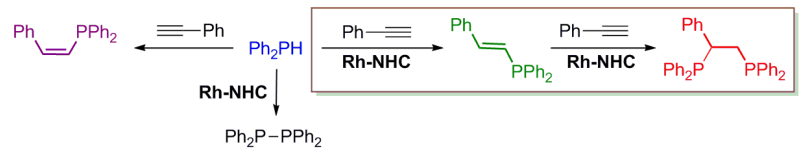

Figure 1. Monitoring of the reaction between phenylacetylene and diphenylphosphine catalysed by 1 a with a molar ratio $20: 40: 1$ in tol- $d_{8}$ at $100^{\circ} \mathrm{C}$.

In order to get information on the mechanism, the reaction of phenylacetylene with diphenylphosphine catalysed by 1 a (5 mol\%) was monitored by ${ }^{31} \mathrm{P}$ NMR. As is shown in Figure 1 the amount of $\mathrm{Ph}_{2} \mathrm{PH}(\diamond)$ decrease with a sigmoidal shape. In the early stage of the reaction $(2 \mathrm{~h})$ the monophosphination derivative $E$-vinylphosphine $\mathbf{6 a}(\bullet)$ and tetraphenylbiphosphine (a) slowly appeared, in addition with a very smallamount of $Z$ vinylphosphine $5 \mathbf{a}(\Delta)$ and traces of $\mathrm{gem}$-vinylphosphine 4a (not showed). After this initial period, the amount of $E$ vinylphosphine 6 a decreased with the concomitant formation of the 1,2-diphosphinoethane derivative $7 a(\nabla)$. This kinetic profile is compatible with a reaction scheme in which $\mathrm{Ph}_{2} \mathrm{PH}$ reacts initially with phenylacetylene giving rise mainly to the formation of $E$-vinylphosphine, that is subsequently transformed into the 1,2-diphosphine product. The steady increment of the amount of Z-vinylphosphine could be ascribed to the uncatalysed hydrophosphination of phenylacetylene that selectively provides $5 a{ }^{11}$ At the same time, the catalysed dehydrocoupling of $\mathrm{Ph}_{2} \mathrm{PH}$ takes place but at slower rate. Interestingly, $\mathbf{8 a}$ was not formed in the uncatalysed reaction (see Supplementary Information).

Through the monitoring of the catalytic reaction a steady increment of a new set of resonances attributable to a new rhodium species was apparent in the ${ }^{31} \mathrm{P}-\mathrm{NMR}$ spectra. In order to get insight on this species, a stoichiometric reaction between complex 1a and $\mathrm{Ph}_{2} \mathrm{PH}$ was carried out leading to the formation of $\mathrm{RhCl}(\mathrm{IPr})\left(\mathrm{PHPh}_{2}\right)_{2}$ (9) as a result of the cleavage of the chlorido bridges and the substitution of coe by $\mathrm{Ph}_{2} \mathrm{PH}$ (Scheme 2). Complex 9 features two doublet of doublets at $\delta$ $16.4\left(J_{\mathrm{Rh}-\mathrm{P}}=189.1, J_{\mathrm{P}-\mathrm{P}}=52.5 \mathrm{~Hz}\right)$ and $9.7 \mathrm{ppm}\left(J_{\mathrm{Rh}-\mathrm{P}}=118.2, J_{\mathrm{P}-\mathrm{P}}\right.$ $=52.5 \mathrm{~Hz}$ ) in the ${ }^{31} \mathrm{P}\left\{{ }^{1} \mathrm{H}\right\}-\mathrm{NMR}$ spectra which match with those observed in the catalytic reaction. In addition, the ${ }^{13} \mathrm{C}\left\{{ }^{1} \mathrm{H}\right\}-\mathrm{NMR}$ spectrum displays a doublet of doublet of doublets at $\delta 193.3$ $\operatorname{ppm}\left(J_{\mathrm{C}-\mathrm{P}}=122.7, J_{\mathrm{C}-\mathrm{Rh}}=47.1, J_{\mathrm{C}-\mathrm{P}}=16.2 \mathrm{~Hz}\right)$ for the carbene carbon atom. The observation of this complex all along the catalytic reactions strongly suggests that $\mathbf{9}$ could be the resting state of the catalyst.

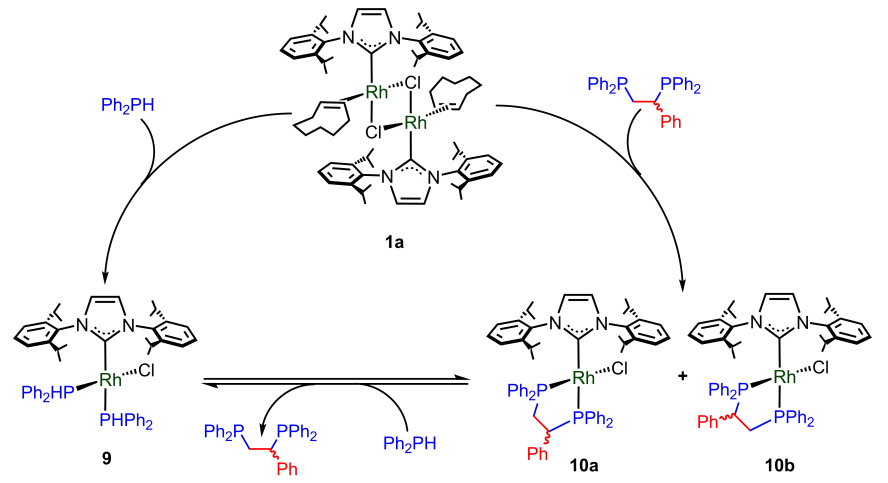

Scheme 2. Stoichiometric reactions on $\mathrm{Rh}^{\prime}$ complexes involved in the double hydrophosphination process.

At this stage of the research, we can postulate that the catalytic cycle follows the classical oxidative addition of the secondary phosphine and subsequent migratory insertion and reductive elimination sequences, firstly for the alkyne and subsequently for the vinylphosphine intermediates, to give rise to the diphosphines. ${ }^{12,10 \mathrm{e}}$ The key point dealing with the efficiency of the Rh-NHC catalyst is its ability to catalyse the double hydrophosphination without being poisoned by the presence of a large excess of the 1,2-diphosphinoethane products. In the Nakazawa's catalytic system, the hard-soft mismatching $\mathrm{Fe} /$ diphosphine and/or the bite angle ${ }^{8,13}$ might account for enhanced catalytic activity, however, this is not applicable to our soft $\mathrm{Rh}^{\prime}$ catalyst. In order to disclose this fundamental point, complex RhCl(IPr)(rac-phenphos) (10) was synthesized by treating $1 \mathbf{a}$ with 2 equiv of rac-phenphos $7 \mathbf{a}$ in toluene (Scheme 2). Complex 10 was obtained in $90 \%$ yield an isolated as a mixture of diastereomers (10a and 10b, molar ratio 98:2). Interestingly, when a solution of 10 in $\mathrm{C}_{6} \mathrm{D}_{6}$ was treated with 2 equiv of $\mathrm{Ph}_{2} \mathrm{PH}$ at $60^{\circ} \mathrm{C}$ an equilibrium between 10 and 9 was established after 5 h (10:9 ratio of 79:21) (Scheme 2), which is in agreement with catalytic performance exhibited by $1 \mathrm{a}$. The lability shown by the diphosphine ligand in $\mathbf{1 0}$ strongly contrasts with the bidentate character of this ligand. Most likely the understanding of this reactivity pattern has to be sought in the influence of the IPr ligand. We hypothesize that the interplay between the steric hindrance and the high trans effect imparted by the NHC ligand is responsible for the destabilization of the chelate phosphine. ${ }^{14}$ In support of this proposal a similar experiment using a related complex without an NHC ligand has been performed. Treatment of $\mathrm{RhCl}\left(\mathrm{PPh}_{3}\right)_{3}$ with 1,2bis(diphenylphosphino)ethane (dppe) leads to the cationic complex $\left[\mathrm{Rh}(\mathrm{dppe})_{2}\right] \mathrm{Cl}$ (11). However, this compound does not react with $\mathrm{Ph}_{2} \mathrm{PH}$ even on heating at $120^{\circ} \mathrm{C}$ for several weeks. Furthermore, the hydrophosphination of phenylacetylene catalysed $\mathbf{1 1}$ provides similar results to the uncatalysed reaction (see Supplementary Information, Table S1). These experiments confirm that the NHC ligand is fundamental to prevent the catalyst deactivation by the destabilization of the chelate complex with the diphosphine.

In conclusion, we have disclosed a Rh-NHC complex able to promote the double hydrophosphination of alkynes that may 
stimulate the rational design of new type of catalyst for the synthesis of bis-phosphorous containing compounds. The carbene ligand plays a major role in the catalytic system due to its particular stereoelectronic properties that prevent the poisoning of catalytic species by strong coordination of the diphosphine product. The optimization of the catalytic system by fine tuning of the NHC ligand, including the design of catalysts able to promote the enantioselective double hydrophosphination of alkynes, as well as DFT studies on the mechanism are currently underway.

Financial support from the Spanish Ministerio de Economía y Competitividad (MEC/FEDER) under the Project (CTQ201342532-P), the Diputación General de Aragón (DGA/FSE-E07) and Fondo Social Europeo, the CONSOLIDER INGENIO-2010 under the Project MULTICAT (CSD2009-00050) and the Campus Iberus are gratefully acknowledged. The authors also thank the support of King Fahd University of Petroleum \& Minerals (KFUPM) under the KFUPM-University of Zaragoza research agreement. ADG thanks the "Subprograma de Formación Posdoctoral" from the Spanish Ministerio de Economía y Competitividad.

\section{Notes and references}

1 (a) D. S. Glueck, Chem. Eur. J. 2008, 14, 7108; (b) P. Merino, E. Marqués-López, R. P. Herrera, Adv. Synth. Catal. 2008, 350, 1195; (c) A. Kondoh, H. Yorimitsu, K. Oshima, Chem Asian. J. 2010, 5, 398. (d) S.-I. Kawaguchi, A. Ogawa, Synlett 2013, 24, 2199; (e) J.-L. Montchamp, Acc. Chem. Res. 2014, 47, 77.

2 (a) F. Alonso, I. P. Beletskaya, M. Yus, Chem. Rev. 2004, 104, 3079; (b) D. Zhao, R. Wang, Chem. Soc. Rev. 2012, 41, 2095; (c) L. Rosenberg, ACS Catal. 2013, 3, 2845; (d) V. Koshti, S. Gaikwad, S. H. Chikkali, Coord. Chem. Rev. 2014, 265, 52.

3 (a) M. A. Kazankova, I. V. Efimova, A. N. Kochetkov, V. V. Afanas'ev, I. P. Beletskaya, P. H. Dixneuf, Synlett 2001, 497; (b) F. Jerome, F. Monnier, H. Lawicka, S. Derien, P. H. Dixneuf, Chem. Commun. 2003, 696; (c) K. Takaki, G. Koshoji, K. Komeyama, M. Takeda, T. Shishido, A. Kitani, K. Takehira, J. Org. Chem. 2003, 68, 6554; (d) A. D. Sadow, I. Haller, L. Fadini, A. Togni, J. Am. Chem. Soc. 2004, 126, 14704; (e) A. M. Kawaoka, T. J. Marks, J. Am. Chem. Soc. 2005, 127, 6311; (f) B. Liu, T. Roisnel, J.-F. Carpentier, Y. Sarazin. Angew. Chem. Int. Ed. 2012, 51, 4943; (g) K. J. Gallagher, R. L. Webster, Chem. Commun. 2014, 50, 12109; (h) M. B. Ghebreab, C. A. Bange, R. Waterman. J. Am. Chem. Soc. 2014, 136, 9240.

4 (a) A. Allen Jr., D. R. Manke, Tet. Lett. 2000, 41, 151; (b) L. L. Khemchyan, J. V. Ivanova, S. S. Zalesskiy, V. P. Ananikov, I. P. Beletskaya, Z. A. Starikova, Adv. Synth. Catal. 2014, 356, 771.

5 (a) A. Allen Jr., L. Ma, W. Lin, Tet. Lett. 2002, 43, 3707; (b) J. J. Stone, R. A. Stockland Jr., J. M. Reyes Jr., J. Kovach, C. C. Goodman, E. S. Tillman, J. Mol. Catal. A, Chem. 2005, 226, 11; (c) T. Mizuta, C. Miyaji, T. Katayama, J.-I Ushio, K. Kubo, K. Miyoshi, Organometallics 2009, 28, 539;

6 (a) R. B. King, P. N. Kapoor, J. Am. Chem. Soc. 1969, 91, 5191; (b) P. M. Treichel, W. K. Wong, J. Organomet. Chem. 1978, 157, C5; (c) J. L. Bookham, D. M. Smithies, A. Wright, M. Thornton-Pett, W. McFarlane, J. Chem. Soc., Dalton Trans. 1998, 811; (d) S. A. Pullarkat, D. Yi, Y. Li, G.-K. Tan, P.-H. Leung, Inorg. Chem. 2006, 45, 7455.

7 A. Kondoh, H. Yorimitsu, K. Oshima, J. Am. Chem. Soc. 2007 129, 4099.
8 M. Kamitani, M. Itazaki, C. Tamiya, H. Nakazawa, J. Am. Chem. Soc. 2012, 134, 11932

9 (a) A. Di Giuseppe, R. Castarlenas, J. J. Pérez-Torrente, M. Crucianelli, V. Polo, R. Sancho, F. J. Lahoz, L. A. Oro, J. Am. Chem. Soc. 2012, 134, 8171; (b) R. Azpiroz, A. Di Giuseppe, R. Castarlenas, J. J. Pérez-Torrente, L. A. Oro, Chem. - Eur. J. 2013, 19, 3812; (c) L. Palacios, M. J. Artigas, V. Polo, F. J. Lahoz, R. Castarlenas, J. J. Pérez-Torrente, L. A. Oro, ACS Catal. 2013, 3, 2910; (d) R. Azpiroz, L. Rubio-Pérez, A. Di Giuseppe, V. Passarelli, F. J. Lahoz, R. Castarlenas, J. J. PérezTorrente, L. A. Oro, ACS Catal. 2014, 4, 4244.

10 (a) V. P. W. Bohm, M. Brookhart, Angew. Chem., Int. Ed. 2001, 40, 4694-4696; (b) J. D. Masuda, A. J. Hoskin, T. W. Graham, C. Beddie, M. C. Fermin, N. Etkin, D. W. Stephan, Chem. Eur. J. 2006, 12, 8696; (c) L.-B. Han, T. D. Tilley, J. Am. Chem. Soc. 2006, 128, 13698; (d) R. Waterman, Organometallics 2007, 26, 2492; (e) A. M. Geer, A. L. Serrano, B. de Bruin, M. A. Ciriano, C. Tejel, Angew. Chem., Int. Ed. 2015, 54, 472.

11 F. Alonso, Y. Moglie, G. Radivoy, M. Yus, Green.Chem. 2012, 14, 2699. See also Table S1 in Supplementary Information.

12 V. P. Ananikov, I. P. Beletskaya, Chem. Asian J. 2011, 6, 1423.

13 (a) Y. Matsuura, Y. Tanaka, M. Akita, J. Organomet Chem. 2009, 694, 1840; (b) R. Langer, F. Bönisch, L, Maser, P. Pietzonza, L. Vondung, T. P. Zimmermann, Eur. J. Inorg. Chem. 2015, 141.

14 (a) W. A. Herrmann, Angew. Chem. Int. Ed. 2002, 41, 1290; (b) A. J. Arduengo III, L. I. Iconaru, Dalton Trans. 2009, 6903; (c) S. Díez-González, N. Marion, S. P. Nolan, Chem. Rev. 2009, 109, 3612; (d) M. N. Hopkinson, C. Richter, M. Schedler F. Glorius, Nature 2014, 510, 485; (e) J. A. Mata, F. E. Hahn, E. Peris, Chem. Sci. 2014, 5, 1723. 